Proceedings of SALT 31: 145-165, 2021

\title{
English non-manner how-clauses as answers to deficient questions*
}

\author{
Rebecca Jarvis \\ University of California, Berkeley
}

\begin{abstract}
English exhibits a variety of embedded how-clause that, while introduced by a canonically interrogative item, lacks an intuitive sense of interrogativity. This paper offers an analysis of the semantics of these clauses that is grounded interrogative semantics. On this view, how in these clauses introduces a degenerate, necessarily-singleton question set. Further, the paper observes that how here introduces a factive presupposition that cannot be reduced to the matrix predicate's entailments. Accordingly, this paper supports a view on which factivity can arise from multiple sources. A diachronic-based account is also offered to explain the reccurence of how in non-manner embedded clauses cross-linguistically.
\end{abstract}

Keywords: factivity, non-manner how-clauses, interrogative, clausal complementation

\section{Introduction}

An obvious property of interrogatives is that they can occur either in a matrix context or embedded under a predicate. In this paper, I focus on a type of embedded clause, headed by how, that breaks this symmetry. How, as a canonical question word, has a number of different uses:

(1) a. We found out [how Carl was dancing] (namely, clumsily). MANNER

b. We found out [how Allyson spells her name] (namely, first $a$, then $l . .$. ).

METHOD

c. We found out [how hot it was yesterday] (namely, 90²). DEGREE

d. We found out [how (in the world) Geoff was still asleep] (namely, because he didn't fall asleep until 5am).

PROPOSITIONAL-HOW (Pak 2017)

From these interrogative uses, we can distinguish a fifth type of embedded how-clause, which I will term a complementizer-like how-clause (CHC); the term follows Nye (2013). The following examples all have a salient CHC parse:

* I thank Diti Bhadra, Rajesh Bhatt, Ivano Caponigro, Gennaro Chierchia, Emily Clem, Amy Rose Deal, Peter Jenks, Kristina Liefke, Wataru Uegaki, Carla Umbach, Yimei Xiang, and audience members at SALT 31, UC Berkeley, and UC San Diego for comments and discussion.

(C)2021 Jarvis 
(2) a. They told me how the tooth fairy doesn't really exist. (Legate 2010:1) $\approx$ they told me that the tooth fairy doesn't really exist (and she doesn't!)

b. We talked about how this snowstorm was totally unexpected.

c. It's funny how people always want what they don't have.

Each of these sentences has a interrogative-how construal (or perhaps multiple interrogative construals, with different uses of how). Sentence (2a), for instance, has a propositional-how construal, on which the interlocutors informed the speaker of how the world came to be such that there is no tooth fairy in it. However, there is also another available reading, the $\mathrm{CHC}$ reading, on which the speaker was simply informed of the tooth-fairy's nonexistence and takes this to be a true fact. This paper focuses on this latter reading.

Here, I aim to address two main questions. The first concerns the compositional semantics of English CHCs like (2a). As we will see, CHCs distribute like embedded interrogatives, but they lack an intuitive sense of interrogativity. The question thus arises of how to account for their intuitive parallel to non-interrogative thatclauses but also their formal and distributional parallel to embedded questions. To explain this pattern, I propose an analysis of CHC semantics on which they denote a singleton set of propositions, with CHC how additionally adding a presupposition of the complement's truth. This analysis formally parallels Uegaki's (2015) account of that-clauses (on which those clauses denote singleton sets of propositions).

The second question concerns why, of all wh-items, how is used in CHCs: other wh-items like who and why do not permit CHC-like interpretations. This question is particularly salient because non-manner uses of how can be found in multiple languages, for instance German (3) and Greek (4): ${ }^{1}$

Anna sah wie Berta ihre Tasche packte. Anna saw how Berta her bag packed

'Anna saw Berta packing her bag.'

(Umbach et al. 2021:3)

$$
\begin{aligned}
& \text { Nomizo pos milise sti Maria. } \\
& \text { think-1SG how talked-3 SG to-the Mary } \\
& \text { 'I think that he talked to Mary.' }
\end{aligned}
$$

(Roussou 2020:13a)

I propose a largely diachronic explanation for this pattern. In particular, I suggest that how's status as an adjunct makes it more salient for reanalysis as originating within the clause's left periphery.

1 The semantics of non-manner how-clauses in both Greek and German differs substantially from that of English CHCs. For clarity, I reserve the term $\mathrm{CHC}$ to discuss the English construction and its semantics, reserving the broader term non-manner how-clause (following Umbach, Hinterwimmer \& Gust (2021)) for analogous constructions in other languages. 
This paper proceeds as follows. $§ 2$ presents the data that my account of English CHC semantics aims to capture; I lay out key generalizations and also discuss assumptions I make about CHC syntax. From there, $\$ 3$ presents an analysis of the semantics of English CHCs and compares this account to a prior account of English CHCs by Liefke (2021). I turn in $\S 4$ to look more broadly at non-manner uses of how and offer a conjecture as to why how, relative to other wh-items, is more often used with a non-canonical or non-interrogative function. $\$ 5$ concludes.

\section{Empirical generalizations}

This section sets out generalizations regarding the semantics of CHCs that the analysis will aim to capture. At present, there is a limited amount of work on the syntax (Legate 2010; Nye 2013; Jarvis to appear) or semantics (Liefke 2021) of English CHCs. ${ }^{2}$ In $\$ 2.1$, I overview assumptions that I make about CHC syntax, based largely on Legate's (2010) characterization. In $\$ 2.2$, I present three core generalizations about $\mathrm{CHC}$ semantics that my analysis is designed to capture.

\subsection{Syntactic assumptions}

This account relies upon two assumptions about the syntax of CHCs. The first concerns their category: CHCs are syntactically DPs. The second concerns the location of CHC how: it is base-generated in the left periphery and does not move from within the clause. In this section, I briefly overview evidence for both of these claims.

\subsubsection{Category: CHCs are DPs}

Most work on CHC syntax (Legate 2010; Jarvis to appear, pace Nye 2013) treats CHCs as DPs. This characterization largely relies on distributional differences between that-clauses and CHCs. For instance, Legate notes that CHCs cannot occur in positions that are not assigned Case:

It was conceded $\{$ that $/ *$ how $/ *$ [the fact that $]\}$ the tooth fairy doesn't exist. (Legate 2010:7)

Here, we see that CHCs appear to require Case, while that-clauses do not. Legate takes this as evidence of a syntactic-category distinction between the two, with $\mathrm{CHCs}$ behaving like Case-requiring DPs.

2 Umbach et al. (2021) also offers a characterization of the semantics of German non-manner howclauses, an analogue of CHCs with different properties and distribution. See $\$ 3.2 .4$ for some differences between English and German non-manner how-clauses. 
Similar evidence comes from predicates that can take either PP or that-clause complements. Here, CHCs can occur under the PP, while that-clauses cannot:

They told me about $\{*$ that/how/[the fact that] $\}$ the tooth fairy doesn't exist.

(Legate 2010:2)

Again, we see CHCs patterning with true DPs rather than that-clauses. Based on evidence like this, Legate (2010) concludes that CHCs are syntactically DPs. (See her work and Jarvis (to appear) for more arguments.)

\subsubsection{Location: No movement}

A second assumption is that $\mathrm{CHC}$ how is base-generated in its surface location in the left periphery of the clause. Umbach et al. (2021), following the characterization of English by Legate (2010), show extensively that wie 'how' in German non-manner how-clauses does not leave behind a gap; analogous argumentation also applies to English.

Their argument relies upon the well-established fact that the trace of a moving item occupies a syntactic position which cannot be simultaneously filled by another item (Chomsky 1981). For instance, in a manner-how question, the trace left by how prevents us from including another manner adverbial in the question:

* How manner did you dance gracefully?

If $\mathrm{CHC}$ how moves from within the clause, we would expect it to leave behind a gap, just as in the manner question above. However, we can find no such evidence:

a. They told me how (they don't think) you worded the letter properly.

MANNER (Legate 2010:26)

b. We talked about how Mary won the prize by taking one small step at a time.

METHOD

c. We talked about how it was 90 degrees out yesterday. DEGREE

d. We talked about how John's still sleeping because he didn't get to sleep until 6am.

PROPOSITIONAL-HOW

As Legate concludes, CHCs are "semantically complete" (p.130): minimally, CHC how does not leave behind a trace that corresponds to any interrogative use listed in (1) above. Based on this and other evidence, Legate concludes that CHC how is base-generated in its surface location in the left periphery.

The exact location that CHC how occupies (whether the $\mathrm{C}$ head or Spec,CP) has been debated (Legate 2010; Nye 2013), and it is not crucial for our compositional account. Specifier-to-head reanalysis is a common pattern in the CP domain (Gelderen 2008), and it is not relevant to us exactly which left-peripheral position CHC how occupies in Present-Day English. 
Non-manner how-clauses

\subsection{Semantic generalizations}

With this background, I now turn to a set of three semantic generalizations that my account aims to capture: that $\mathrm{CHCs}$ are factive in interpretation, that they distribute like (a subtype of) embedded interrogatives, and that they are intuitively non-interrogative. I lay out each generalization in turn.

\subsubsection{Factivity}

A first generalization, implicit in the paraphrase given in (2a) earlier, is that $\mathrm{CHCs}$ are factive in interpretation. Legate (2010) asserts that CHCs involve a truth presupposition, and Nye (2013) and Liefke (2021) also assume a similar presupposition. Evidence for this point comes from the observation that CHCs are factively-interpreted even when embedded under predicates that otherwise do not require their complements to be true.

This can be seen with predicates like tell and agree (on), both of which can embed declaratives, interrogatives, and CHCs. Declarative complements to both predicates are non-veridical:

(9) a. They told me that the tooth fairy doesn't exist (but I don't believe it).

b. The children agreed that Santa really exists.

Interrogative complements to these predicates, too, are non-veridical. (See Tsohatzidis (1993) and Spector \& Egré (2015) with regard to tell.) That is, the agent need not stand in relation to the true answer to the embedded question, as can be seen in the following examples:

(10) a. Every day, the meteorologists tell the population where it will rain the following day, but they are often wrong. $\quad$ (Spector \& Egré 2015:20)

b. The children all agreed on whether Santa really exists. They all think he exists, even though that isn't true.

These predicates thus do not generally introduce a factive presupposition (or any veridical inference).

However, CHCs under these predicates still are factively interpreted. Legate notes that CHCs under tell cannot be questioned or denied by the speaker; (9a) is coherent, but (11) is not.

(11) They told me how the tooth fairy doesn't exist (\#but I don't believe it).

(Legate 2010:15)

A similar pattern holds for agree on, which can embed CHCs (12a). A CHC with a false complement is infelicitous (12b) in a way that its that-clause counterpart (9b) 
is not: ${ }^{3}$

(12) a. The children agreed on how they'd had a great vacation.

b. \# The children agreed on how Santa really exists.

These patterns suggest that the inference of truth in $\mathrm{CHCs}$ cannot be reduced to the presupposition-inducing behavior of matrix predicates.

A seeming counterexample to the factivity of $\mathrm{CHCs}$ comes from highly quotative contexts with communication predicates:

(13) a. The point for your average voter is that if they see the EDL marching through their streets shouting about... how the UK is going to be Islamified by 2040, they are also receiving these cues from other sections of British society.

(Nye 2013:53)

b. My uncle keeps telling me about increasingly ridiculous conspiracy theories. Last week, he told me all about how squirrels have microphones in their tails now, which was a new one!

In examples like these (which are most naturally accompanied in speech by exaggerated and highly marked prosodic contours), the speaker clearly does not endorse the content of the $\mathrm{CHC}$ or presuppose its truth. Accordingly, these examples provide a clear challenge to the factivity generalization.

However, we can note that in other, similarly highly-quotative contexts, other sentence types - notably including exclamatives — can also lack an inference of factivity:

My uncle went on and on about what a scam tofu is.

Exclamatives, similarly to $\mathrm{CHCs}$, are often analyzed as factive (Zanuttini \& Portner 2003). Accordingly, it seems that the most likely explanation for these patterns is that the loss of factivity observed in examples like (13a) is more a property of quotation than of $\mathrm{CHCs}$ per se. ${ }^{4}$ I will thus maintain the generalization that $\mathrm{CHCs}$ are factive, and the account developed below will incorporate a truth presupposition.

3 I thank Ivano Caponigro for discussion of this point and Emily Clem for the examples in (9b) and (12b).

4 Formalizing this is an avenue for future work, but one possible explanation is that a silent supposedlylike operator takes scope over the $\mathrm{CHC}$ content. Such a move is motivated by the observation that adding overt supposed(ly) would yield appropriately-factive sentences in these contexts:

(i) a. My uncle told me (about) [how squirrels supposedly have microphones in their tails].

b. My uncle told me (about) [what a supposed scam tofu is].

Though other avenues are certainly possible, it seems clear that these examples are not patterning like Free Indirect Discourse (Sharvit 2008; Eckardt 2014). In FID, indexicals like today in (2a) can shift; in contrast, no shifting is permitted in CHCs (2b): 
Non-manner how-clauses

\subsubsection{Resolutive-like distribution}

Our third generalization, following Nye (2013), is that CHCs only occur as complements of responsive predicates. Following Lahiri (2002), we can partition interrogative-embedding complements into two groups: rogative predicates like wonder and ask require an agent to stand in relation to a full semantic question, while responsive predicates like know, tell, and be certain place an agent in relation to an answer to a question. Nye's (2013) corpus work suggests that CHCs occur under the latter set of predicates.

Specifically, on Nye's characterization, CHCs can be embedded under cognitive factives, emotive factives, and communication verbs. Examples of each of the following are shown below:
a. Cognitive factive (e.g., remember):
I remembered how I'd never won a single race in elementary school.
b. Emotive factive (e.g., funny):
It's funny how people always want what they don't have.
c. Communication verb (e.g., tell):
She told me how she couldn't stand her new neighbor.

Nye's work is restricted to predicates that directly select for $\mathrm{CHC}$, wh-, and thatclause complements, with no extra prepositions involved for any type of complement. The true range of predicates that can embed CHCs is in fact somewhat broader. As observed earlier, other responsive predicates like agree (on) can also embed CHCs. While such predicates fall outside of Nye's purview because agree does not take a preposition when embedding a that-clause, Nye's generalization appears to extend to such cases.

By contrast, $\mathrm{CHCs}$ cannot be embedded under rogative predicates:

$$
\text { * They asked/wondered how }{ }_{\mathrm{CHC}} \text { the tooth fairy doesn't exist. }
$$

Though an interrogative parse of the embedded clause is available (as expected), a $\mathrm{CHC}$ construal is unavailable. A fully satisfactory account should explain why this is the case.

Further, we can observe that $\mathrm{CHCs}$ cannot be embedded under predicates like believe that are traditionally analyzed as uninterrogative (Lahiri 2002):

(ii) a. John looked at my picture. [Yes, he thought, he wanted to marry me today (三 that day).] (Sharvit 2008:4)

b. When I talked to my friend two weeks ago, he told me all about how he had way too much work to do that day ( $\not \equiv$ today).

This contrast suggests that, however one might analyze the loss of factivity in quotative CHC contexts, it cannot be ascribed to a wholly FID-like semantics. 
* Susan believes how the tooth fairy doesn't exist.

Thus, it is clear that CHCs do not fully distribute like that-clauses. Instead, we maintain the generalization that they are restricted to responsive predicates.

\subsubsection{Non-interrogativity}

In our initial description of the $\mathrm{CHC}$ reading, we saw that the $\mathrm{CHC}$ reading is distinct from the canonical interrogative uses of how. While how-containing embedded clauses always have an interrogative reading, this reading can be distinguished from the $\mathrm{CHC}$ one. When an agent stands in relation to an embedded question under a responsive predicate $(x V s Q)$, she stands in relation to an answer to that question and thus also stands in relation to a proposition $p$ that contains some additional element (e.g., manner/method/reason) not contained in the surface form of $Q$. By contrast, the agent with a $\mathrm{CHC}$ need not be concerned about any such additional element (as in the earlier discussion of (2a).

The CHC reading, though it contains how, thus lacks the intuitive interrogative flavor of interrogative how. The account will aim to explain how and why a canonically interrogative item like how is used in this non-interrogative way in CHCs.

\section{CHCs as answers}

In this section, I develop an account that captures our three empirical generalizations. To begin, we will consider one salient hypothesis that straightforwardly accounts for the factivity of CHCs: namely, we assume that CHC how is semantically identical to a factive complementizer.

\subsection{Hypothesis: CHCs as factive that-clauses}

One popular enterprise aims to reduce the presuppositional behavior of embedded interrogatives to that of embedded declaratives. In this vein, Spector \& Egré (2015) argue that interrogatives embedded under a responsive predicate $P$ are veridically interpreted if and only if declarative complements of $P$ are veridically/factively interpreted. On such a view, the declarative complementizer that is semantically vacuous, and any presuppositional behavior of the complement results from the choice of embedding predicate.

However, there is reason to think that complementizers may play a more active role than they do on this view. Evidence for this comes from languages like Greek with richer complementizer systems. In Greek, one complementizer, $p u$, has been traditionally analyzed as factive (Christidis 1982) and contrasts with a different 
complementizer oti. Both complementizers can occur under the predicate thimame 'remember', but with different presuppositional behavior:

a. Thimame oti ton ixa sinandisi sto Parisi - an ke bori remember.1SG OTI him had met at Paris however it may na kano lathos.

PRT make.1SG error

'I remember that I had met him in Paris - however I may be wrong.'

(Roussou 1992:9a)

b. \# Thimame pu ton ixa sinandisi sto Parisi - an ke bori na remember.1SG PU him had met at Paris however it may PRT kano lathos.

make.1SG error

'I remember meeting him in Paris - however I may be wrong.' 5

(Roussou 1992:9b)

Here, the truth of the oti-headed clause can be questioned by the speaker, while the truth of the $p u$-clause cannot be. While the precise characterization of the distinction between oti and $p u$ has been a matter of continuing debate (for an overview, see Angelopoulos 2019), it seems clear that we must ascribe some additional component of meaning to some but not other declarative complements. That is, the presuppositional behavior of a Greek complement is not entirely predictable from the embedding predicate.

A common way to account for this is to ascribe presuppositional behavior onto a complementizer itself; there are many implementations of such a system that propose a distinct factive complementizer that ${ }_{F}$ (Chierchia 1984, 2019; Kratzer 2006, i.a.). For the present purposes, the exact implementation is not crucial. At a broad level, we can imagine giving CHC how the same denotation as that $F$. Indeed, Liefke (2021) suggests an analysis on which how in some ${ }^{6}$ CHCs has the same semantics as Kratzer's that $F$ :

$$
\llbracket \text { how }_{\mathrm{CHC}} \rrbracket^{i}=\llbracket \text { that }_{\mathrm{F}} \rrbracket^{i}=\lambda p: p_{i} \cdot\left[\lambda j: p_{j} \wedge\left(\forall k\left(p_{k} \wedge k \leq j\right) \rightarrow k=j\right)\right]
$$

On this account CHC how takes in a proposition $p$, imposes the presupposition that $p$ holds in the evaluation situation $i$, and returns a set of $p$ 's minimal exemplifiers.

Such an account, by design, can capture the factivity of $\mathrm{CHCs}$, but it offers little explanation of the observed distribution of CHCs. In particular, it is not entirely clear why CHCs should occur under non-factive predicates like tell and agree on.

5 Roussou marks this example with the symbol!.

6 Liefke offers a two-part characterization of English CHCs on which some are denotationally equivalent to factive that-clauses and others are events-in-progress (the latter of which follows Umbach et al.'s (2021) account of German non-manner how-clauses). 
These predicates usually would not select for that ${ }_{F}$-headed clauses, so it is difficult to explain why they should be able to select CHCs. To explain the distributional behavior, such an account requires a certain degree of selection by fiat.

For this reason, I will reject the proposal of directly adopting a ready-made factive complementizer's semantics for the semantics of CHC how. Our goal, in a way, will be to construct a different sort of factive-complementizer-like denotation, but one that can account for the interrogative-like distribution of CHCs. To do this, I propose taking interrogative semantics as the basis for a semantics of CHCs.

\subsection{CHCs as "deficient" questions}

In this account, I will rely on the standard assumption (Hamblin 1973; Karttunen 1977) that a question and proposition have different types. Specifically, I treat a proposition as type $\langle s, t\rangle$, while a question is an $\langle\langle s, t\rangle, t\rangle$ set of propositions. I will leverage this type difference to explain restrictions on the distribution of $\mathrm{CHCs}$.

At this point, we face a choice point regarding our assumptions of how embedded questions serve as arguments to responsive predicates. There are two salient possibilities: either directly (with the matrix predicate semantically taking an $\langle\langle s, t\rangle, t\rangle$ object), or with the relation between the two mediated by an answerhood operator. The former strategy involves postulating interrogative-taking variants of matrix predicates and has recently been advanced by Spector \& Egré (2015) and Uegaki (2020), among others, while the latter has a long history including Heim (1994) and Dayal (1994). At its core, this account can be made compatible with either approach. However, the former strategy offers a slightly more explanatory view of the distributional patterns of CHCs. To see this, we will briefly consider the answerhood-operator strategy.

\subsubsection{CHCs and answerhood operators}

On this view, answerhood operators mediate the relationship between an interrogative complement and its embedding predicate. We take Dayal's (2016) ANS-D as an example of such an operator:

$$
\llbracket \mathrm{ANS}-\mathrm{D}(\mathrm{Q}) \rrbracket=\lambda w . \imath p\left[p_{w} \wedge p \in Q \wedge \forall p^{\prime}\left[\left[p_{w}^{\prime} \wedge p^{\prime} \in Q\right] \rightarrow p \subseteq p^{\prime}\right]\right]
$$

This operator applies to a $\langle\langle s, t\rangle, t\rangle$ set $Q$ and a world $w$ and returns the maximal true answer $p$ in $Q$. Accordingly, it returns a proposition that is necessarily true in $w$.

In this framework, we can treat CHC how as Partee's (1987) IDENT type-shifter, shifting its complement from a proposition into the set that contains it:

$$
\llbracket \text { how }_{\mathrm{CHC}} \rrbracket=\lambda p_{\langle s, t\rangle} \cdot \lambda q_{\langle s, t\rangle} \cdot p=q
$$


Then, we can use the ANS-D operator to type-shift from an interrogative type back to a propositional one. In this process, the ANS-D operator allows for the introduction of a truth presupposition of the CHC complement $p$ in world $w$ (since $p$ is the only element in $\{p\}$, the presupposition of ANS-D cannot be satisfied if $p$ is not true in w). Hence, we derive the factivity of CHCs.

Such a move, however, crucially relies upon the identification of the world $w$ with the evaluation world $w_{0}$. However, this is not generally the case: under nonveridical predicates like agree on, for instance, ANS-D applied to an interrogative complement should not necessarily yield a proposition that is true in the evaluation world. To account for the factivity of CHCs under agree on, then, we must assume that CHCs always associate with a factivity-introducing ANS operator, even though predicates like agree on would not normally select for or require this sort of operator. This reduces the explanatory power of this account. By contrast, the direct approach does not require this sort of maneuver.

\subsubsection{CHCs and the direct approach}

As we turn now to the direct account, we will begin with a similar approach to the previous section. In particular, one benefit of the denotation of CHC how given in (21) is that it captures the non-interrogativity of CHCs. Conventionally, an interrogative consists of a set of propositions, each of which corresponds to an answer to the question. Treating CHCs as singleton sets as in (21) thus gives them an interrogative type, but does not add additional interrogative-associated material. ${ }^{7}$

This in itself, however, is insufficient to capture the meaning of a CHC. In particular, it cannot capture the factivity of CHCs. This is because we cannot reduce the factivity of $\mathrm{CHCs}$ entirely to the entailments introduced by matrix predicates. On the direct approach, there is no additional ANS-like operator to incorporate factivity of CHCs with predicates like agree on. Accordingly, we will incorporate an additional presupposition of factivity into the meaning of CHC how. In particular, I will take this as a precondition on constructing the set containing the complement:

$$
\llbracket \text { how }_{\mathrm{CHC}} \rrbracket^{w_{0}}:=\lambda p_{\langle s, t\rangle}: p_{w_{0}} \cdot\{p\}
$$

This introduces a presupposition of the complement's truth in the evaluation world.

In a way, then, we have constructed effectively a factive complementizer with a non-standard type. This allows us to address restrictions on the distribution of $\mathrm{CHCs}$. For one, we can capture the fact that $\mathrm{CHCs}$ cannot occur under rogative

7 Note that in a standard Karttunen approach to interrogative semantics, type-shifting in this way is the contribution of the $[+Q] \mathrm{C}$ head. If one assumes that $\mathrm{CHC}$ how syntactically occupies a specifier position, it would be possible to separate this meaning contribution out from how itself (which might then just introduce a truth presupposition, as below). 
predicates. This can be explained by Uegaki's (2015) non-triviality presupposition for rogatives: ${ }^{8}$

«wonder/ask/inquire $\rrbracket_{w}(Q)(x)$ is defined only if $x$ can believe both of the following:

(Uegaki 2015:45)
a. $\lambda w . \exists p \in Q[p(w)=1]$
b. $\lambda w . \exists p \in Q[p(w)=0]$

(there is a true proposition in $Q$ )

(there is a false proposition in $Q$ )

Since CHCs are necessarily-singleton sets, a coherent speaker cannot believe that the single proposition $p$ in $\{p\}$ is simultaneously true and false. Thus, CHCs cannot occur under rogative predicates.

Further, we can capture the fact that $\mathrm{CHCs}$ cannot occur under anti-rogative predicates like believe. This is readily captured by the question-like semantic type of $\mathrm{CHCs}$, on the assumption that believe necessarily selects only for $\langle s, t\rangle$ propositions.

\subsubsection{Matrix predicate contributions}

This account presents a fairly minimial view of CHC semantics, where they only presuppose the truth of their complement and lift the complement's type. However, some prior work (especially Nye (2013)) argues for a stronger semantics for CHCs. Her evidence comes from sentences like the following:

A note on a bathroom door in the Chicago headquarters warned workers to remember [how/\#that - when they were on a high after winning the Iowa caucuses - Hillary Clinton had shocked them with a primary victory].

(Nye 2013: 76-77, Nye's judgment)

Here, Nye argues that the CHCs "convey something additional to the basic fact of a factive that-clause complement" (p.176-177). This raises the question of whether we need to encode more in the semantics of CHC how. I will suggest here that we do not, and that we can instead ascribe this behavior to properties of individual matrix predicates.

8 This formulation of the presupposition requires an account of polar questions on which such questions denote a multimembered set, in contrast to singleton-set approaches like that of Biezma \& Rawlins (2012). The account of CHCs developed here also, at least at this point, appears similarly to require a multimembered approach to polar questions in order to capture the different between know how CHC $p$ and know whether $p$. The notion of highlighting in polar questions (Roelofsen \& Farkas 2015) may offer a way to bridge these analyses, though I leave a full discussion of this to future work. Note that $\mathrm{CHCs}$ and polar questions presumably differ in whether they presuppose truth within the complement clause (as with $\mathrm{CHCs}$ ) or not, but know later imposes a veridicality requirement with interrogative complements that is trivial for CHCs. 
Non-manner how-clauses

For the English speakers that I have consulted, the contrast that Nye reports in (24) is not especially clear-cut. However, a main location where CHCs and thatclauses diverge in interpretation is in rising declaratives with know and remember:

You know that I went to Rome last year? (Who told you?!/\#Well, later I...) You know how ${ }_{\mathrm{CHC}}$ I went to Rome last year? (Well, later I.../\#Who told you?!)

Here, the rising declarative with the that-clause expresses the speaker's surprise about the addressee's knowledge. By contrast, the variant with the CHC does not. Instead, it functions as a topic-raiser, perhaps to begin some larger story.

This pattern seems to be restricted to know and remember. Given this, it seems most promising to assume that the difference in meaning here relates to the meaning of these matrix predicates, not to CHCs themselves. In particular, it has long been observed that at least know is sensitive to the distinction between DPs and CPs, which more or less maps on to the distinction between familiarity and factual knowledge; some languages, like French and German, realize this type of difference overtly (King 2002; Moltmann 2013, i.a.). Since CHCs have been argued to be syntactic DPs (Legate 2010), it seems reasonable that the differences we observe in (25) and (26) result from the differing syntactic categories of $\mathrm{CHCs}$ and that-clauses: CHCs are selected by the DP-taking, familiarity-denoting variant of know, while that-clauses are selected by the CP-taking variant. Because the two variants of know are different lexical items, we no longer expect $\mathrm{CHC}$ and that-clause complements to pattern together; namely, DP-selecting know can check whether the agent the agent is familiar with the $\mathrm{CHC}$ complement, rather than whether she has factual knowledge of it's truth. On this account, we can attribute the contrast observed here, and also in (24), to the contributions of different matrix predicates and do not need to encode it in the meaning of a CHC. ${ }^{9}$

\subsubsection{Comparisons to previous accounts}

Liefke (2021) offers the only other existing account of the semantics of English CHCs. The present account, though it shares several general notions with her account (both accounts ascribe a semantics resembling a factive complement to at least some $\mathrm{CHCs}$ ), offers a few advantages.

For one, the present account offers a more explanatory view of which matrix predicates can embed CHCs. As mentioned earlier, Liefke suggests that English

9 Such an analysis would require the familiarity denotation of know to be sensitive only to syntactic category and to be flexible in terms of semantic type, and it would also require an explanation of what it means to be familiar with (a set of) propositions. I leave the resolution of these questions to future work. 
$\mathrm{CHCs}$ come in two varieties. One of these varieties of CHC how carries the denotation of Kratzer's (2006) minimal-situation that $t_{F}$. This account does not explain why predicates like tell and agree (on) that usually do not take factive complements can embed CHCs.

On her account, the other variety of $\mathrm{CHC}$ denotes an event-in-progress. This variety of CHC has the same denotation as Umbach et al. (2021) give to German non-manner how-clauses. Accordingly, her account predicts that matrix predicates that license German non-manner how-clauses should also license CHCs.

However, this is not the case. German non-manner how-clauses are licensed under fictive verbs like dream and imagine, with local projection of the complement:

$$
\begin{aligned}
& \text { Er wachte vor Lachen auf, weil er geträumt hatte, wie er einen } \\
& \text { he woke from laughing up because he dreamed had how he a } \\
& \text { Witz erzählte. } \\
& \text { joke told } \\
& \text { 'He woke up laughing because he dreamed that he had told a joke.' }
\end{aligned}
$$

(Umbach et al. 2021:f.n. 5a)

Here, the joke-telling occurred only in the dream world, not in the real one. This contrasts with the behavior of CHCs in English: ${ }^{10}$

(28) \# He dreamed about how a unicorn was prancing in the sun.

In contrast to (27), this $\mathrm{CHC}$ is infelicitous if the unicorn existed only in the dream. Accordingly, Liefke's account additionally overgenerates regarding which English CHCs are licensed.

\section{Why how?}

The account developed here treats $\mathrm{CHC}$ how as retaining some core properties of an interrogative-namely, generating an $\langle\langle s, t\rangle, t\rangle$ set of propositions-while, unlike standard interrogative items, introducing a necessarily singleton-set (and a factive presupposition). The account accordingly assumes lexical ambiguity between an interrogative variant (or variants) of how and the $\mathrm{CHC}$ one. A natural question, then, is why CHCs use how: why do other English wh-items like who or what not give rise the same sort of ambiguity?

This question is also made more salient by the observation that, as we saw earlier, we can find non-interrogative how-headed embedded clauses in a number of other languages. Examples of such clauses in German and Greek, as seen earlier in (3)-(4).

10 This example parallels an example that Liefke offers with the predicate imagine; I find both the imagine and dream sentences similarly infelicitous. 
The question of why how recurs with this sort of non-interrogative usage naturally arises.

\subsection{CHCs as products of reanalysis}

I propose a largely diachronic explanation of this phenomenon. On such an account, $\mathrm{CHC}$ and other non-interrogative uses of how rely on the reanalysis of the wh-item as originating within the left periphery of the clause rather than moving into it. Such reanalysis, I suggest, is especially available to how because of two factors. First, CHC how is an adjunct; and second, it has a broad range of interrogative uses. Both of these, I suggest, make how more likely than other wh-items to be reanalyzed.

Because how is an adjunct $w h$-item, the surface string that follows it in an embedded question is grammatical on its own. In this way it contrasts with argument wh-items, as shown below:

$$
\begin{aligned}
& \text { a. ... who [те Mary thanked] } \\
& \text { b. ... how [TP Mary danced] } \\
& \text { c. ... that [Tе Mary danced] }
\end{aligned}
$$

The predicate thank is necessarily transitive, so an object-less sentence like *Mary thanked is ungrammatical. Accordingly, forming a grammatical parse of the bracketed TP in (29a) requires recognizing an object gap corresponding to movement of who. In contrast, because how is an adjunct, the bracketed portion of (29b), Mary danced, is grammatical as is. (To interpret the embedded question, we must recognize that $w h$-movement has occurred, but this does not impact the grammaticality of the TP on its own.) In this way, how resembles other items like that (29c) that are base-generated within the $\mathrm{CP}$, since they similarly embed fully grammatical TPs. This parallel, I suggest, makes how more available to reanalysis than argument wh-items like who.

A parallel, semantically-oriented argument centers on Simons, Beaver, Roberts \& Tonhauser's (2017) notion of question entailments. On this view, a proposition is entailed by a question if it is entailed by every member of the question's Hamblin/Karttunen $(\mathrm{H} / \mathrm{K})$ set. Again by virtue of how's being an adjunct, the question how $p$ ? entails the gapless proposition $p$ : in a question like How did Mary dance?, every element of the $\mathrm{H} / \mathrm{K}$ set $\{$ that Mary danced gracefully, that Mary danced slowly, ... \} entails that Mary danced in some manner and, consequently, that Mary danced. By contrast, with an argument wh-question like Who danced?, there is no way to treat danced as a proposition in the same way.

A second facet that, I suggest, also plays a role in how's widespread use in non-interrogative constructions is the fact that interrogative how already has a wide number of uses. Especially because of propositional-how uses, any proposition $p$ can 
be questioned with how. This contrasts with some other adjunct wh-items like where and when, which are mostly restricted to enquiring about events. This, I suggest, makes how especially prone to reanalysis as a complementizer-like element, due to its higher frequency and more general distribution (making it perhaps a sort of default).

\subsection{Predictions}

A diachronic account of CHCs makes two predictions. First, non-manner howclauses should not occur in all languages, since how might undergo reanalysis in some but not all languages. Second, it raises the possibility that other $w h$-items besides how could also be reanalyzed in a similar way, because the semantics of interrogative how does not directly give rise to the $\mathrm{CHC}$ reading. I argue that both of these predictions are borne out.

\subsubsection{Languages without $\mathrm{CHCs}$}

First, though we have noted that other languages do have non-manner how-clauses, this is not universal. For instance, Chinese (Nye 2013), Hindi (Rajesh Bhatt, p.c.), and Thai (Peter Jenks, p.c.) all lack non-interrogative how-headed embedded clauses of this sort. This is consistent with a diachronic, reanalysis-based account of CHCs (and, potentially, other non-manner how-clauses), since whether reanalysis occurs is a language-particular fact.

Based on this very small sample of languages, we can conjecture that a parameter that may be relevant to whether a language has non-manner how-clauses is whether embedded questions in the language involve obligatory $w h$-movement. All three of these languages are $w h$-in-situ languages, though Hindi allows for some scrambling of $w$ h-items (Bhatt \& Dayal 2007). If such a pattern holds up more broadly, it would lend further support to a reanalysis-based account: how should only be reanalyzed as originating in an embedded clause's left periphery if it is seen to surface in that position. A total lack of $w h$-movement would serve as counterevidence against treating how as base-generated within the left periphery.

\subsubsection{Eventive when-clauses}

Second, a diachronic account predicts that other $w h$-items may be reanalyzed in a similar fashion in the history of some languages. This, too, I argue, may be borne out. Here, I turn to a type of embedded when-clause that Hall \& Caponigro (2010) term an eventive when-clause:

$$
\text { I really hated [when John lied like that]. }
$$

(Hall \& Caponigro 2010:17) 
This sentence has a reading on which the speaker hated the event of John's lying. This contrasts with the expective interrogative reading, on which the speaker hated that John lied at the particular time (say, 2pm) that he did.

Hall and Caponigro analyze these clauses as free relatives on events, with when originating within the clause within a silent PP and moving into the left periphery, leaving behind a broadly type-e trace. On this account, when is lexically ambiguous. It always modifies a type- $\langle e, t\rangle$ predicate and can restrict it either to times (for temporal when-clauses) or events:

$$
\begin{aligned}
\text { a. } & \llbracket \text { when }_{1} \rrbracket & =\lambda P \lambda x[P(x) \wedge \operatorname{time}(x)] \\
\text { b. } & \llbracket \text { when }_{2} \rrbracket & =\lambda P \lambda x[P(x) \wedge \operatorname{event}(x)]
\end{aligned}
$$

A later $\delta$ operator applies the $\imath$ type-shifter to extract the unique relevant time/event.

Like CHCs, eventive when-clauses lack the standard interrogativity of an embedded clause. However, I have not pursued a free-relative based analysis of CHCs. This was largely to capture the interrogative-like distribution of CHCs. A further reason for such an approach was because $\mathrm{CHCs}$ are gapless. By contrast, an accout like Hall \& Caponigro's (2010) would predict gaps within this type of clause.

In fact, eventive when-clauses may be more parallel to CHCs than Hall \& Caponigro's (2010) account predicts. In particular, we can observe that eventive when-clauses, too, are gapless. Temporal when-clauses, certainly, are not:

$$
\text { * I read [when you recommended at 5pm]. (Hall \& Caponigro 2010:23) }
$$

This sentence is ungrammatical if $5 \mathrm{pm}$ was the recommended time for reading. This is strong evidence for when moving and leaving behind a temporal trace.

Eventive when-clauses, by contrast, behave somewhat differently. Here, analogously to the arguments that we saw in (8) for CHCs, we see that we can insert an extra temporal argument:

$$
\text { Remember [when I accidentally celebrated at 11pm last New Years Eve]? }
$$

This suggests that, if eventive when-clauses do have a gap, it is certainly not a temporal one (though, to be clear, it remains possible that there may be a gap of a different sort). Perhaps, then, we cannot fully unify temporal and eventive whenclauses as in Hall and Caponigro's approach. By contrast, if eventive when-clauses are gapless, they more closely resemble CHCs.

At this point, it is tempting to see eventive when-clauses as somewhat parallel to $\mathrm{CHCs}$, but with a different interrogative item. Certainly, this parallelism only extends so far, as the two are not semantically equivalent. Eventive when-clauses require their complement to denote an event. Eventive when-clauses with non-event-denoting embedded clauses are deviant:

?? I hated [when the tooth fairy didn't exist]. 
This sentence suggests a highly marked context in which the tooth fairy flitted in and out of non-existence, and her period of non-existence was hated by the speaker. This amounts to coercion of nonexistence into an event. Eventive when-clauses are thus more restricted with respect to what their complements can denote than English CHCs are.

A similar restriction to events has been previously noted for some languages' non-manner how-clauses. In particular, Umbach et al. (2021) characterize German non-manner how-clauses as having the same restriction. Nonexistence sentences are similarly restricted in German non-manner how-clauses:

\# Sie erzählten mir, wie die Zahnfee nicht wirklich existiert.
they told me how the tooth fairy not really exists
'They told me that the tooth fairy doesn't really exist.' (Liefke 2021:2b)

Accordingly, the restriction that we see on eventive when-clauses parallel one that is known to be relevant in non-manner how-clauses. While a full analysis of eventive when-clauses and of the typology of non-manner how-clauses is beyond the scope of the present work, it seems not impossible that eventive when-clauses might offer a parallel to CHCs with a different reanalyzed $w h$-item. This would lend further support to a reanalysis-based account of CHC how.

\section{Conclusion}

This paper has investigated the semantics of CHCs, a type of embedded how-clause. To explain the distribution and factive presupposition of CHCs, I have proposed an account on which CHCs occupy an intermediate position between interrogatives and standard that-clauses: CHCs have the type of a question but, unlike ordinary questions, do not denote a standardly multimembered set. I also offered a potential explanation, grounded in diachronic reanalysis, for why we see how used in CHCs.

At its core, the account presented here suggests that factivity does not arise in a single way across all varieties of complement clauses. In some cases, factivity may arise from the embedding predicate (as is assumed by e.g. Spector \& Egré (2015)). $\mathrm{CHCs}$, in contrast, provide evidence against treating all factive inferences as arising in this way. Instead, CHCs serve as an example in which factivity must arise from the complement itself.

\section{References}

Angelopoulos, Nikolaos. 2019. Complementizers and Prepositions as Probes: Insights from Greek: UCLA PhD dissertation. 
Non-manner how-clauses

Bhatt, Rajesh \& Veneeta Dayal. 2007. Rightward scrambling as rightward remnant movement. Linguistic Inquiry 38(2). 287-301. doi:10.1162/ling.2007.38.2.287.

Biezma, María \& Kyle Rawlins. 2012. Responding to alternative and polar questions. Linguistics and Philosophy 35. 361-406. doi:10.1007/s10988-012-9123-z.

Chierchia, Gennaro. 1984. Topics in the Syntax and Semantics of Infinitives and Gerunds: University of Massachusetts, Amherst PhD dissertation.

Chierchia, Gennaro. 2019. Factivity meets polarity: On two differences between Italian vs. English factives. In Daniel Altshuler \& Jessica Rett (eds.), The Semantics of Focus, Degrees and Times: Essays in Honor of Roger Schwarzschild, 111-134. Springer. doi:10.1007/978-3-030-04438-1_6.

Chomsky, Noam. 1981. Lectures on government and binding. Dordrecht: Foris Publications. doi:10.1515/9783110884166.

Christidis, Anastasios-Fivos. 1982. Oti/pos-pu: Complementizer selection in Modern Greek. In Studies in Greek Linguistics, vol. 2, 113-177.

Dayal, Veneeta. 2016. Questions (Oxford Surveys in Semantics and Pragmatics 4). Oxford University Press.

Dayal, Veneeta Srivastav. 1994. Scope marking as indirect wh-dependency. Natural Language Semantics 2(2). 137-170. doi:10.1007/BF01250401.

Eckardt, Regine. 2014. The semantics of free indirect discourse: How texts allow us to mind-read and eavesdrop. Leiden: Brill.

Gelderen, Elly van. 2008. Renewal in the left periphery: Economy and the complementiser layer. Transactions of the Philological Society 107(2). 131-195. doi:10.1111/j.1467-968X.2009.01216.x.

Hall, David P. \& Ivano Caponigro. 2010. On the semantics of temporal when-clauses. In Semantics and Linguistic Theory (SALT) 20, 544-463. doi:10.3765/salt.v20i0.2566.

Hamblin, Charles. 1973. Questions in Montague grammar. Foundations of Language 10(1). 41-53.

Heim, Irene. 1994. Interrogative semantics and Karttunen's semantics for "know". In Rhonna Buhalla \& Anita Mittwoch (eds.), Israeli Association for Theoretical Linguistics (IATL) 1, 128-144.

Jarvis, Rebecca. to appear. Presuppositionality and syntactic nominalization in finite clausal complements. In West Coast Conference on Formal Linguistics (WCCFL) 39, Cascadilla Proceedings Project.

Karttunen, Lauri. 1977. Syntax and semantics of questions. Linguistics and Philosophy 1(1). 3-44.

King, Jeffrey C. 2002. Designating propositions. The Philosophical Review 111(3). 341-371. doi:10.1215/00318108-111-3-341.

Kratzer, Angelika. 2006. Decomposing attitude verbs. Talk given at The Hebrew University of Jerusalem. 
Lahiri, Utpal. 2002. Questions and Answers in Embedded Contexts. Oxford: Oxford University Press.

Legate, Julie Anne. 2010. On how how is used instead of that. Natural Language and Linguistic Theory 28(1). 121-134. doi:10.1007/s11049-010-9088-y.

Liefke, Kristina. 2021. Non-manner 'how'-complements in English and German. In Patrick Georg Grosz, Luisa Martí, Hazel Pearson, Yasutada Sudo \& Sarah Zobel (eds.), Sinn und Bedeutung (SuB) 25, 563-580. London. doi:10.18148/sub/2021.v25i0.954.

Moltmann, Friederike. 2013. Abstract objects and the semantics of natural language. Oxford: OUP. doi:10.1093/acprof:oso/9780199608744.001.0001.

Nye, Rachel. 2013. How complement clauses distribute: Complementiser-how and the case against clause type: Universiteit Gent $\mathrm{PhD}$ dissertation.

Pak, Marjorie. 2017. Propositional how questions and negation. In Aaron Kaplan, Abby Kaplan, Miranda K. McCarvel \& Edward J. Rubin (eds.), West Coast Conference on Formal Linguistics (WCCFL) 34, 423-430. Somerville, MA: Cascadilla Proceedings Project.

Partee, Barbara H. 1987. Noun phrase interpretation and type-shifting principles. In Jeroen Groenendijk, Dick de Jongh \& Martin Stokhof (eds.), Studies in discourse representation theory and the theory of generalized quantifiers, 115143. Dordrecht: Foris. doi:10.1515/9783112420027-006.

Roelofsen, Floris \& Donka F. Farkas. 2015. Polarity particle responses as a window onto the interpretation of questions and assertions. Language 91(2). 111-178. doi:10.1353/lan.2015.0017.

Roussou, Anna. 1992. Factive complements and wh-movement in Modern Greek. UCL Working Papers in Linguistics 4. 123-147.

Roussou, Anna. 2020. Complement clauses: Case and argumenthood. In Ludovico Franco \& Paolo Lorusso (eds.), Linguistic Variation: Structure and Interpretation. Studies in Honor of M. Rita Manzini, vol. 132 Studies in Generative Grammar, 609-632. Berlin: Mouton de Gruyter. doi:10.1515/9781501505201030.

Sharvit, Yael. 2008. The puzzle of free indirect discourse. Linguistics and Philosophy 31. 353-395. doi:10.1007/s10988-008-9039-9.

Simons, Mandy, David Beaver, Craige Roberts \& Judith Tonhauser. 2017. The best question: Explaining the projection behavior of factives. Discourse Processes 54(3). 187-206. doi:10.1080/0163853x.2016.1150660.

Spector, Benjamin \& Paul Egré. 2015. A uniform semantics for embedded interrogatives: an answer, not necessarily the answer. Synthese 192. 1729-1784. doi:10.1007/s11229-015-0722-4.

Tsohatzidis, Savas L. 1993. Speaking of truth-telling: The view from whcomplements. Journal of Pragmatics 19. 271-279. doi:10.1016/0378- 
Non-manner how-clauses

2166(93)90032-k.

Uegaki, Wataru. 2015. Content nouns and the semantics of question-embedding. Journal of Semantics 33(4). 623-660. doi:10.1093/jos/ffv009.

Uegaki, Wataru. 2020. The existential/uniqueness presupposition of whcomplements projects from the answers. Linguistics and Philosophy 44. 911951. doi:10.1093/jos/ffv009.

Umbach, Carla, Stefan Hinterwimmer \& Helmar Gust. 2021. German wiecomplements: Manners, methods, and events in progress. Natural Language and Linguistic Theory doi:10.1007/s11049-021-09508-z.

Zanuttini, Rafaella \& Paul Portner. 2003. Exclamative clauses: At the syntaxsemantics interface. Language 79(1). 39-81. doi:10.1353/lan.2003.0105.

Rebecca Jarvis

1203 Dwinelle Hall

Berkeley, CA 94720 USA

rjarvis@berkeley.edu 